\title{
TSH-DEFICIENCY IS ASSOCIATED WITH A LOWER THYROID GLAND VOLUME IN HYPOPITUITARIC PATIENTS COMPARED TO HEALTHY VOLUNTEERS: A CROSS-SECTIONAL STUDY
}

Santi $\mathrm{D}^{1,2}$, Brigante $\mathrm{G}^{1,2}$, Gnarini $\mathrm{V}^{1,2}$, Madeo B ${ }^{1,2}$, De Vincentis $\mathrm{S}^{1,2}$, Carani $\mathrm{C}^{1,2}$, Faustini-Fustini $\mathrm{M}^{3}$, Balestrieri $\mathrm{A}^{4}$, Rochira $\mathrm{V}^{1,2}$

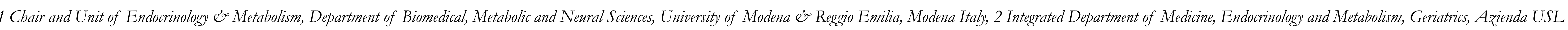
of Modena, NOCSAE of Baggiovara, Modena, Italy,3 Endocrine unit, Dept. of Medicine, Bellaria Hospital, Bologna, 4 Department of medicine, endocrine and metabolism unit, Ospedale "M. Bufalini", Asl of Cesena.

\section{INTRODUCTION}

Thyroid Volume (TV) depends on age, gender, anthropometry, smoking and iodine status (1). Furthermore, IGF-1 plays a significant role on thyroid growth, as demonstrated both in acromegaly (2) and GH-deficiency (3). Traditionally, thyroid growth is considered to be TSH-dependent in both physiologic and pathological conditions $(4,5)$. The aim of the study is to evaluate the long-term effect of TSH-deficiency on TV in hypopituitaric patients compared with healthy volunteers.

\section{MATERIALS and METHODS}

We performed a cross-sectional, controlled study on $\mathbf{5 8}$ hypopituitaric patients (36 male, 22 female) with multiple hormonal deficiency (mean age: 60.0 \pm 13.9 years), and 244 volunteers ( 73 male, 171 female) (mean age: $47.7 \pm 11.63$ years). The main inclusion criteria was the confirmed diagnosis of central hypothyroidism. All subjects underwent thyroid ultrasonography (Siemens Acuson Antares ${ }^{\circledR}$, Philadelphia, USA) performed by the same operator. TV was calculated as the sum of TV of the two lobes, each estimated as: length $(\mathrm{cm}) \mathrm{x}$ width $(\mathrm{cm}) \times$ depth $(\mathrm{cm}) \times 0.52$. The body surface area $(B S A)$ was calculated by using the formula: [weight $(\mathrm{kg}) \times$ height $(\mathrm{cm}) / 3600] / 2](7)$.

Figure 3

\section{Thyroid volume $(\mathrm{mL})$}

$\square$ All patients $\square$ Patients without nodules $M$ Patients with nodules

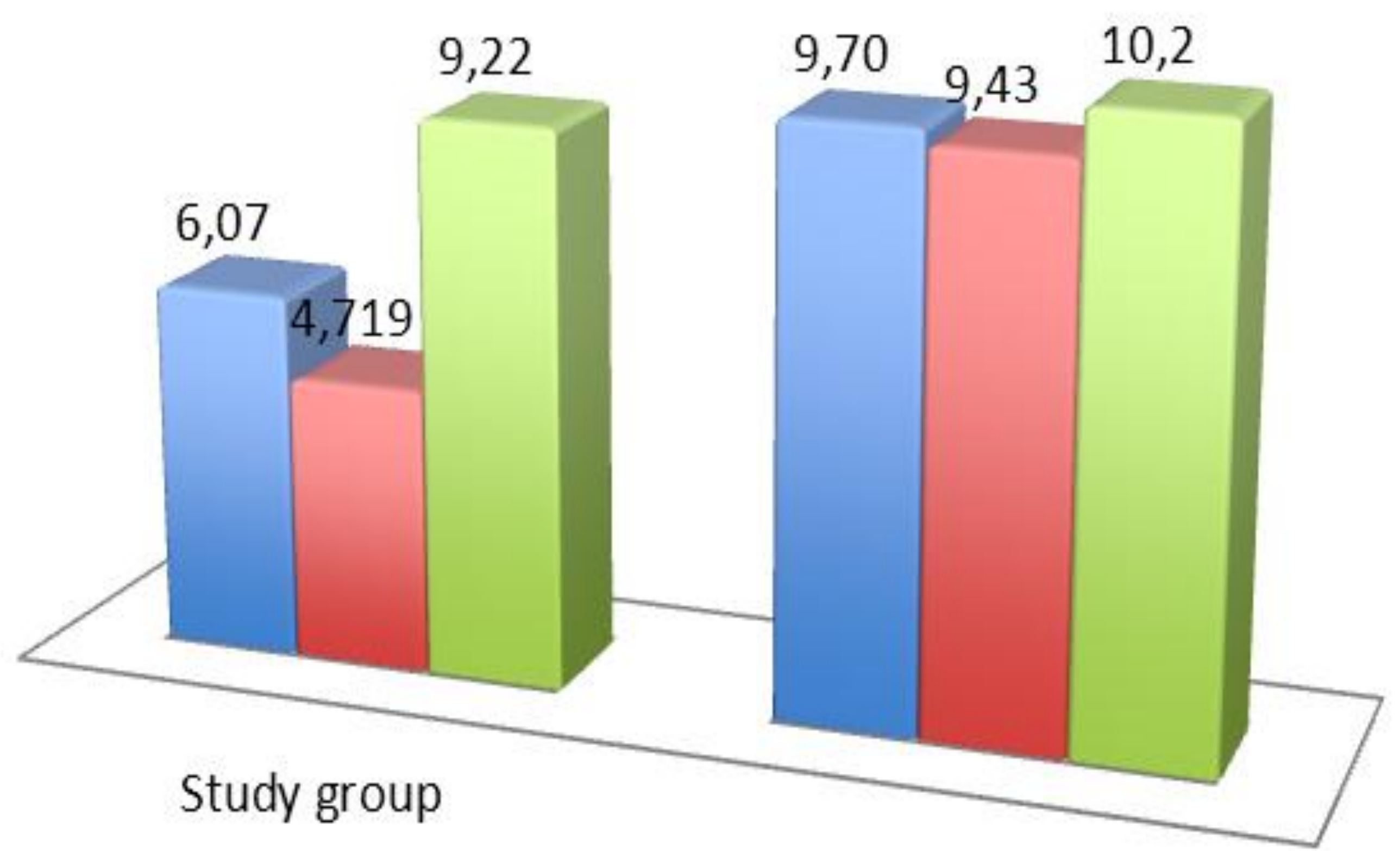

Control group

\section{RESULTS}

Age, weight, body mass index (BMI) and BSA were significantly greater in hypopipuitaric patients than healthy volunteers $(p<0,001)$. Thyroid nodules were incidentally discovered at ultrasonography in 17 hypopituitaric (29.3\%) (Fig.1) and 93 volunteers (38.1\%) (Fig.2). Characteristics of healthy volunteers were recently published by our group (8). TV was lower in hypopituitaric patients than in volunteers $(6,066 \pm 5,079 \mathrm{~mL}$ and $9,695 \pm 3,702 \mathrm{~mL}, \mathrm{p}<0,001$ ) (Fig.3). This difference was confirmed also in the subgroup of patients without thyroid nodules (mean $4,719 \pm 3,230 \mathrm{~mL}$ and 9,430 $\pm 3,497 \mathrm{~mL}, \mathrm{p}<0,001$ ), but it was not confirmed when hypopituitaric patients and volunteers with nodular goiter were compared each other (Fig.3). Finally, TV was lower in hypopituitaric patients without nodules $(4,73+3,27$ $\mathrm{mL})$ than in those with goiter $(9,62 \pm 7,18 \mathrm{~mL})(p=0.003)$. These differences were held even after the correction of TV for BSA, $\mathrm{BMI}$ and age.

Study Group

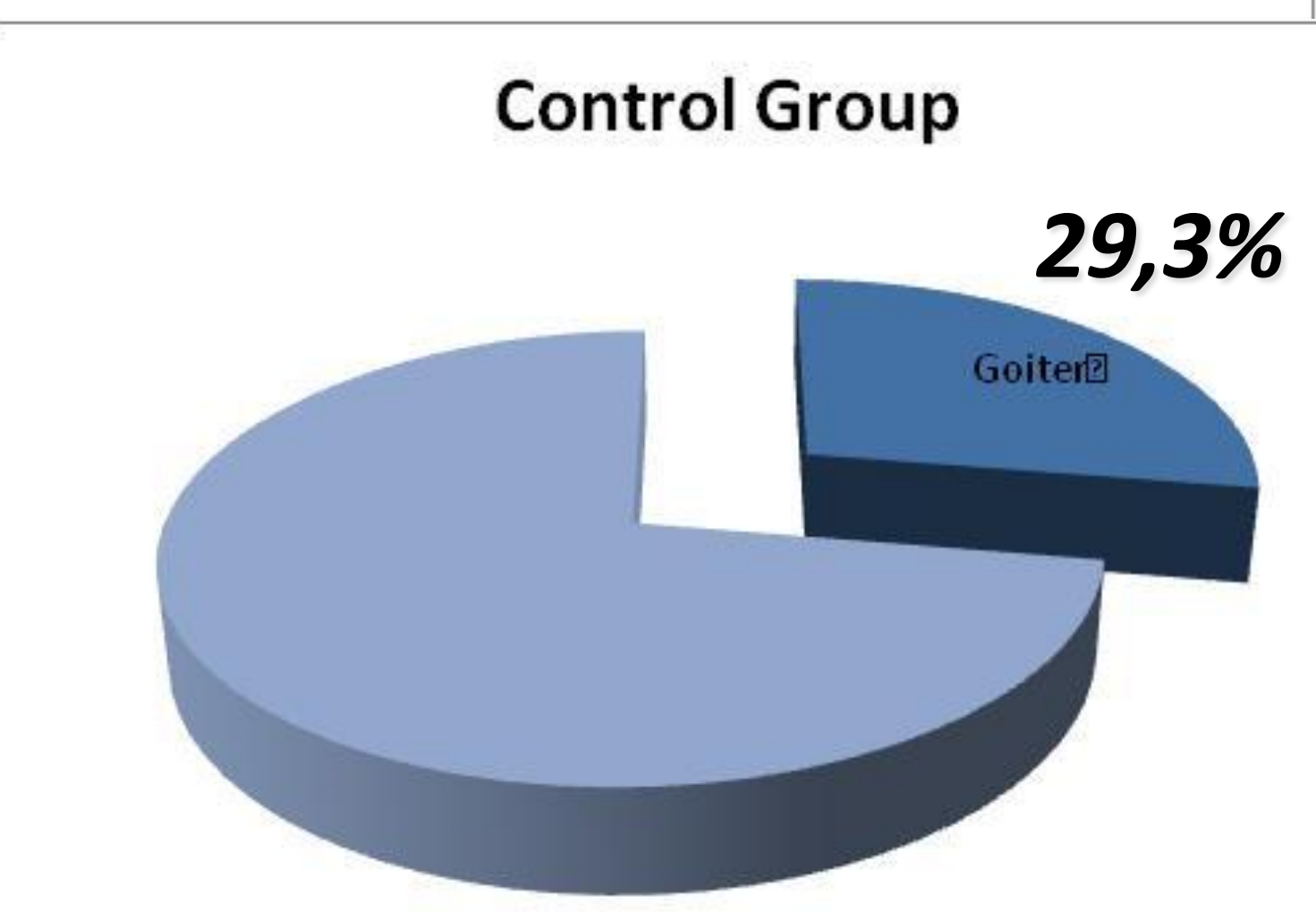

Figure 2.

Prevalence of goiter in

healthy subjects

\section{DISCUSSION}

TV is significantly lower in hypopituitaric patients than in healthy subjects, but the prevalence of thyroid nodules seems to be similar between two groups. However, the reduction of TV in hypopituitaric patients seems to occur only in thyroid glands without nodules. Since the TV is similar in patients with TSH deficiency and in controls, the chronic lack of TSH, as in hypopituitarism, seems to be responsible in vivo for a reduction of TV, but this effect seems to operate mainly within the normal thyroid tissue rather than in hyperplastic nodular tissue.

\section{REFERENCES}

(1) Hegedus, L. et al. Journal of Clinical Endocrinology and Metabolism, 56, 260+263; (2) Rolleston HD. Oxford university press, London. 1936; (3) Alcantara MR et al. J Clin Endocrinol Metab 2006, 91:860-864; (4) Dumont JE, et al. Baillieres Clin Endocrinol Metab. 1991 Dec;5(4):727-54; (5) Larsen PR 2002 Williams' Textbook of Endocrinology. 10th ed. W.B. Saunders; 331-373; (6) Thomas GA et al. IARC Sci Publ 1999;147:45-59; (7) Mosteller RD. N Engl J Med. 1987 Oct 22;317(17):1098; (8) Gnarini V. et al. J Endocrinol Invest 2013 